\title{
A NEW THERAPEUTIC DIATHERMY ELECTRODE
}

BY

FranK W. LAW

THE electrode here described was designed for use in the treatment of certain diseases of the eye by the diathermy current. Hitherto the current has been applied to the eye by means of a simple circular zinc or lead electrode fixed in a rubber band which encircles the head; the advantages over this form which are claimed for the new electrode are :-

1. The head-band can be applied firmly and securely indepen- $\overrightarrow{0}$ dently of the electrode, the pressure of which upon the eye is capable of separate adjustment. With the former instrument the $\&$ pressure of the head-band was transmitted directly to the eye.

2. The construction of the electrode allows of close and accurate apposition to the eye whatever the facial conformation.

3. The efficiency of the application is increased, as witnessed by the fact that the milliampere-meter readings with the new electrode are constantly lower than with the old type.

4. The comfort of the patient is greatly increased.

A sketch of the electrode is shown in Fig. 1. It consists of base plate which is introduced beneath two rubber flaps on the re-inforced head-band; the ends of the band are pierced by holes, and the band is secured at the proper tension round the head by fastening over a button at the appropriate holes. Into the base plate is fitted, by means of a rotatory joint, a stem which is broken by a flat joint with a milled hand screw-clamp to allow of vertical adjustment of the actual contact piece. The upper end of this stem is pierced by a circular hole through which slides a rod, suitably curved at the contact end; this rod is again secured by a thumb-screw. Provision is made in the stem for the reception and fixation of the insulated lead from the apparatus. The actual

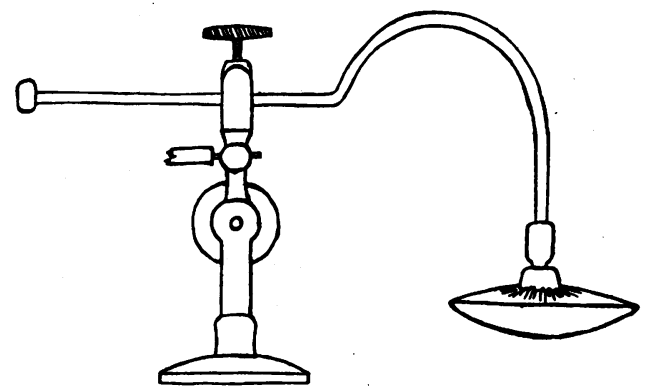

Fig. 1. 
contact piece is attached to the end of the rod by a ball and socket joint, which permits accurate apposition to the eye. It will be seen that adjustment of the apparatus in all planes is provided for.

The apparatus is adjusted by applying the head-band comfortably and firmly round the forehead, passing just above the occipital protuberance behind. A small pad of wool, soaked in saline, is placed upon the closed eye so as to fill the concavity within the orbital margin; a thin layer of wool, similarly soaked. is applied to the contact piece. The latter is then brought down on to the eye and clamped in such a position that contact is accurate and firm; and the whole electrode is then fixed by means

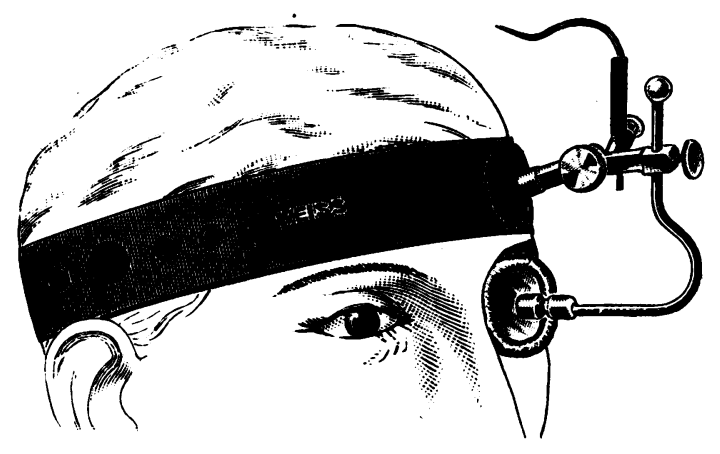

FIG. 2 .

of the thumb-screws. The apparatus in position is illustrated in Fig. 2.

The electrode is made by Messrs. Weiss, of Oxford Street, London, from whom I have heard that many enquiries have been received from purchasers as to the use and application of this electrode in particular and the diathermy current in general; it would, therefore, seem appropriate here to add to the few remarks which were made in this connection at the Oxford Ophthalmological Congress in 1933 (see Trans. Ophthal. Soc. U.K. 1933, p. 474).

With the electrode connected and adjusted as described, and the indifferent electrode applied to the arm, the main current to the instrument is switched on ; care must be taken to see that the head-band is quite dry before this is done. The secondary switch on the apparatus is then moved to the "on " position, and the fine adjustment knob turned until the meter reads 500 milliampères. The actual current which is allowed to pass must always be determined in the end by the patient; a sensation of comfortable heat should be experienced, and this is usually achieved when the indicator is in the neighbourhood of 600 milliampères; individual 
variations occur and must be allowed for. The application usually lasts 10 minutes, and should be given daily if possible, though $\stackrel{9}{\rightarrow}$ in the case of out-patients, three times a week is often the most? that can be arranged.

It is found that the cases which respond favourably to the $\frac{\overline{5}}{\sigma}$ diathermy treatment are those which would ordinarily be expected $\stackrel{\circ}{\circ}$ to benefit from the application of heat-for this is all that the ${ }^{\infty}$ treatment does. There is no known electrical effect produced in $\vec{\bullet}$ the tissues; the only effect, as far as is known, is to raise the $\overrightarrow{\vec{\omega}}$ temperature of the tissues, and the advantage of this particular $\stackrel{\omega}{D}$ form of application consists in its power of penetration; all the $\frac{0}{0}$ tissues between the two electrodes become heated, but since the $\overrightarrow{0}$ active electrode is much smaller than the indifferent, the heat is iv concentrated at and around the eye.

The cases in which the diathermy current finds its most valuableo application are those of subacute glaucoma. On only the rarest occasions does it fail to relieve the tension, and it appears to be ${ }_{\mathbb{D}}$ a definite adjuvant in the action of drugs such as eserine; even more important than the immediate effect is the fact that a daily application for a few days will usually produce a quiet eye, with tension normal or only full, upon which a trephine or sclerotomg $\vec{c}$ operation may be safely performed instead of an emergence iridectomy.

An eye acutely inflamed from any cause is benefited by diatherm $\bar{y}^{2}$. Good results have been achieved in cases of hypopyon ulcer, episcleritis, and interstitial keratitis; threatened or early intra-通 ocular infection, especially after operation or the reception of an intra-ocular foreign body, is well combated by this means. Acute $\vec{\partial}$ and subacute iridocyclitis appear to be considerably helped, and acute choroiditis has been treated with apparent benefit. Diathermy also aids the absorption of abnormal fluids in the vitreous. It is usefully applied in cases of vitreous haemorrhage when the damage? of recurrent haemorrhage is past, and vitreous exudates appear to be absorbed more rapidly when treated by this means. Though it is difficult to see what influence it could have on established nebulae, it has been applied when requested in some cases, andif the patient's statements are to be believed-visual improvement has resulted. Some of the claims which have been made in recommending this form of treatment must be regarded as extravagant, as, for instance, in the treatment of cataract, optic atrophy.. amblyopia, and asthenopia (all of which conditions, and many more ${ }^{N}$ such, have been described as benefiting from diathermv treatment). I have tried, unsuccessfully, to confirm the statement that retinitis? pigmentosa can be usefully treated, but most of the other conditions? have appeared so unlikely to derive any benefit, that the experiment市 has not been made. 
To summarize : diathermy is of proved value in the treatment of acute and subacute glaucoma, and in the majority of cases is effective in relieving pain in any eye disease. In any condition in which it is desirable to apply heat, it affords us a very convenient and the most efficient means to this end.

\section{THE REFRACTIVE ERROR OF TWINS}

BY

\section{FRANK W. LAW}

IN this Journal in $1932 \mathrm{~W}^{2}$ ilson ${ }^{1}$ presented a short but interesting report upon the eye defects of twins, and suggested the value of further information on the matter. Since that time I have come across eight pairs of presumably monozygotic twins, and give here the results of their ophthalmic examination.

Although the patients were submitted to a general physical examination, it is readily admitted that a specialist's knowledge is essential for the final decision as to whether twins are or are not monozygotic. Accordingly, in order to be on the safe side, those twins considered to be monozygotic have not been so labelled, but the less committal term "identical" has been used instead. Three pairs of dissimilar twins were examined, and the results recorded for purposes of comparison.

Identical.

$$
\text { Age R.E. L.E. Remarks }
$$

1. G.E.N. के $21-0.75$ S. $-0{ }^{\circ} 75$ C. $\rightarrow-1^{\circ} 0$ S.

J.H.N. $-2 \cdot 25 \mathrm{~S}$. $-2 \cdot 25 \mathrm{~S}$.

2. I..G. $\quad$ \& $8+3^{\circ} 0 \mathrm{~S} .+2^{\circ} 0 \mathrm{C} . \downarrow+3^{\circ} \mathrm{S} .+1^{\circ} 0 \mathrm{C} . \downarrow$ Both R.C.C.S.

R.G. $\quad+1^{\circ} 0 \mathrm{~S} .+3^{\circ} 0 \mathrm{C} . \downarrow+2^{\circ} 0 \mathrm{~S} .+0^{\circ} 5 \mathrm{C} . \downarrow$ Mother albinoid, with nystagmus.
3. R.C. क $5 \frac{1}{2}+2 \cdot 5 \mathrm{~S}$. $+3 \cdot 25 \mathrm{~S}$.
J.C. $+20 \mathrm{~S}$. $+2{ }^{\circ} \mathrm{OS}$.
"Occasional squint."
R.C.C.S. $20^{\circ}$.

4. D.L. \& $9+1 \cdot 5 \mathrm{~S}$. $+1 \cdot 5 \mathrm{~S}$.
B.L. $\quad+1.5 \mathrm{~S} . \quad+15 \mathrm{~S}$.
D.H. \& $14+0.5 \mathrm{~S}$. $+0.5 \mathrm{~S}$.
J.H. $\quad+0.75 S$.
$+0^{\circ} 5 \mathrm{~S} .+0 \cdot 25 \mathrm{C} . \downarrow$

6. J.C

$$
\text { 우 } 3+2 \cdot 5 \mathrm{~S} .+0{ }^{\circ} \mathrm{C} . \rightarrow
$$

$+2 \cdot 0 \mathrm{~S} .+0.5 \mathrm{C} . \rightarrow$

$+2 \cdot 5 \mathrm{~S} .+0 \cdot 5 \mathrm{C} . \downarrow$

7. A.W. \& $7+3^{\circ} 0 \mathrm{~S} .+2.0 \mathrm{C}$. $\gg$

E.W.

$$
+3.0 \mathrm{~S} .+2 \cdot 5 \mathrm{C} . \rightarrow
$$

8. J.W. \& $8+20$ S. J.W.

$+0.5 \mathrm{~S} .+0.5 \mathrm{C} . \downarrow$

$+3{ }^{\circ} 0 \mathrm{~S} .+20 \mathrm{C} . \mathrm{K}$

$+3^{\circ} 0 \mathrm{~S} .+1^{\circ} 0 \mathrm{C} . \mathrm{K}$

$+20 \mathrm{~S}$.

$+0{ }^{\circ} 5 \mathrm{~S} .+0{ }^{\circ} 5 \mathrm{C} . \downarrow$

Right handed. Both L.C.C.S. at 18 mos.

Left handed.

Both occasional divergence without glasses.

R.C.C.S. $10^{\circ}$.

Slight disparity in size. 